\title{
Carbon Stock Estimation of Urban Trees in Yeka Park and KMU, Addis Ababa
}

\author{
Meseret Habtamu ${ }^{1}$ Mekonnen Amberber ${ }^{2}$ Robel Sahilu ${ }^{2} \quad$ Asnake Gudissa $^{2}$ \\ 1,2 Kotebe Metropolitan University, College of Natural and computational Science, Addis Ababa, Ethiopia
}

\begin{abstract}
Urban forests contribute to climate regulation by controlling GHG emissions. The objective of this study was to estimate the total carbon stock's potential of the Yeka Park Kotebe Metropolitan University and their role in climate change mitigation and enhancement of ecosystem services. There were 4064 trees recorded in the selected study sites in which $27.41 \%$ of the species were indigenous and $72.59 \%$ were exotic trees. The mean above ground and below ground biomass were 160.8 and $69.93 \mathrm{t}$ ha-1 respectively and the mean carbon in the above ground and below ground biomass were 75.56 and $51.75 \mathrm{t}$ ha-1 respectively. The mean $\mathrm{CO} 2$ in the above ground and below ground biomass were 580 and 378.3 t ha-1 respectively. Urban trees reduce atmospheric carbon dioxide through sequestration which is important for climate change mitigation; they also provide different ecosystem services.
\end{abstract}

Keywords: Carbon sequestration, urban forests, biodiversity conservation, Addis Ababa

DOI: $10.7176 / \mathrm{JRDM} / 74-02$

Publication date:March $31^{\text {st }} 2021$

\section{Introduction}

Urban forests are complex system of trees and smaller plants, wildlife, associated organisms, soil, water and air in and around the city. It includes the trees along streets, the landscaping around homes and institutions, the plants in commercial and industrial areas, the multi-layered forests in natural areas and the plants in parks (Walker, 2004).

As Horst (2006) explains urban forestry in Ethiopia has so far received limited attention. Construction within the urban areas and conversion of different land use within the city and the surrounding urban areas has caused the rapid depletion of existing tree cover during the past 100 years. This depletion of green resources has indicated that succeeding city governments had no proper long-term plans to keep the city green with the exception of intervening in some areas such as the establishment of a few parks and roadside plantations under a city beautification program. These interventions also have diverse problems for sustainable management of the urban forest. The main objective of this study is to estimate the total carbon stock's potential of the selected areas and their role in climate change mitigation and enhancement of ecosystem services in Kotebe Metropolitan University (KMU) and Yeka Park. This study provides valuable information on the carbon stock potential of urban forests and ecosystem services in the study area.

The unprecedented rapid urbanization coupled the city's high population growth has been entailing intricacies. The ever growing populations, utilization of fuel wood and charcoal as bio fuel have been contributing to green spaces depletion in Addis Ababa (Gezahegne, 2014). Thus urban forests are largely neglected and need proper management for sustainable urban development. Carbon sequestration potential of urban forests) is hardly studied. Species selection in urban forests is not well planned and needs to be seriously looked to increase ecological and environmental benefit of urban forests.

\section{Materials and Methods \\ Description of the study site}

This study covers the park that is found in Yeka sub city (Yeka Park) and the vegetation that covers Kotebe Metropolitan University (KMU) which are located in Addis Ababa. Addis Ababa city, the capital city of Ethiopia since 1889 lies between $23^{\circ} 21^{\prime} \mathrm{N}$ to $23.35^{\circ} \mathrm{N}$ latitude and $85^{\circ} 20^{\prime} \mathrm{E}$ to $85.33^{\circ} \mathrm{E}$ longitude situated in the central highlands of the country and covers an area of approximately $526 \mathrm{~km}^{2}$ (CSA, 2011).

\section{Data analysis}

The collected data was recorded on excel to analyze the above ground, the below ground biomass, the amount of carbon and $\mathrm{CO}_{2}$ sequestered in each site. The data obtained from DBH, height of each species, and the amount of carbon and $\mathrm{CO}_{2}$ in each park were analyzed using $\mathrm{R}$ software version 3.5.1.

\section{Vegetation survey}

We conducted a reconnaissance survey to have an overall impression and understanding of the study areas. Consequently, we employed a $100 \%$ survey in both study areas to collect the required vegetation data. All trees with $\mathrm{DBH} \geq 5 \mathrm{~cm}$ were identified and their DBH was measured using a diameter Tape. 
We recorded and identified the local names of all woody species to the species level in the field following the Flora of Ethiopia and Eritrea (Edwards et al., 1995, 1997, 2000; Hedberg and Edwards, 1989; Hedberg et al., 2003). For those species, difficult to identify in the field, their specimens were collected and identified in the national herbarium of Ethiopia, Addis Ababa University. The spatial location (latitude and longitude), and elevation of each study area was measured using Suunto Clinometer and Garmin GPS-72 receiver.

\section{Carbon pools to measure}

The following carbons pools were measured in study areas.

1. Above-ground tree biomass (AGB)

2. Below-ground biomass (BGB)

Soil organic carbon was not studied in both study sites because it is not possible to get undisturbed soil. Soil is transported from other areas and manure also added for fertility of the soil. Dead wood were not studied both are collected daily by cleaners.

Above-ground tree biomass (AGB)

The $\mathrm{DBH}$ (at $1.3 \mathrm{~m}$ ) and height of individual trees greater than or equal to $5 \mathrm{~cm} \mathrm{DBH}$ are measured using diameter tape and marking each tree to prevent accidentally counting it twice.

Below-ground biomass (BGB)

One of the most common descriptors of the relationship between root (below-ground) and shoot (above-ground) biomass is the root-to-shoot ratio, which has become the standard method for estimating root biomass from the more easily measured shoot biomass.

To simplify the process for estimating below-ground biomass, it is recommended that root-to-shoot ratio value of 1:5 is used that is, to estimate below-ground biomass as $20 \%$ of above-ground tree biomass (MacDicken, 1997).

\section{Estimation of Carbon in the Above and below Ground Biomass (AGB)}

The selection of the appropriate allometric equation is crucial in estimating aboveground tree biomass (AGB). Terrestrial carbon stock mapping is important for the successful implementation of climate change mitigation policies. Its accuracy depends on the availability of reliable allometric models to infer oven-dry aboveground biomass of trees from census data (Chave et al., 2014). There are different allometric equations that have been developed by many researchers to estimate the above ground biomass. These equations are different depending on the types of species, geographical locations, forest stand types, climate and others.

From the different available allometric equations to estimate the above ground biomass, the model that was developed by (Brown, Gillespie, \& Lugo, 1989) is selected for the study site since the general criteria described by the author are similar to the study area. The general equation that was used to calculate the above ground biomass is given below:

$$
\mathrm{Y}=34.4703-8.0671(\mathrm{DBH})+0.6589\left(\mathrm{DBH}^{2}\right)
$$

Where, $\mathrm{Y}$ is above ground biomass, $\mathrm{DBH}$ is diameter at breast height.

According to (MacDicken, 1997), standard method for estimation of below ground biomass can be obtained as $20 \%$ of above ground tree biomass i.e., root-to-shoot ratio value of 1:5 is used.

$$
\mathrm{BGB}=\mathrm{AGB} \times 0.2
$$

Where, $\mathrm{BGB}$ is below ground biomass, $\mathrm{AGB}$ is above ground biomass, 0.2 is conversion factor (or $20 \%$ of AGB). For both AGB and BGB, the biomass stock density was attained in $\mathrm{Kg} / \mathrm{m} 2$ by means of dividing the sum of all individual tree biomass $(\mathrm{Kg})$ in a plot by the area of the plot $(\mathrm{m} 2)$. The value was converted to ton/ha by multiplying it by 10 . Since the plot areas are part of tropical region, carbon content in the biomass was estimated by multiplying 0.47 while multiplication factor 3.67 was used to estimate $\mathrm{CO}_{2}$ equivalent (Pearson, Walker, \& Brown, 2013).

\section{Diversity and evenness}

Diversity has two components: species richness, or the number of plant species in a given area, and species evenness, or how well distributed abundance or biomass is among species within a community (Wilsey \& Potvin, 2000). The diversity of species in each study site was calculated using the Shannon-Wiener Diversity Index formula. A diversity index is a mathematical measure of species diversity in an area. The Shannon diversity index ( $\left.H^{\prime}\right)$ is used in this study since it is commonly used to characterize species diversity in an area. The Shannon-Wiener Diversity Index ( $\left.\mathrm{H}^{\prime}\right)$ is calculated using the following equation:

$$
\mathrm{H}^{\prime}=-\sum \mathrm{Pi}(\ln \mathrm{Pi})
$$

Where

$\mathrm{Pi}$ is the proportion of each species in the sample.

Shannon's equitability

Shannon's equitability $(\mathrm{EH})$ or evenness is calculated as follows

$\mathrm{EH}=\mathrm{H}^{\prime} / \mathrm{H} \max =\mathrm{H}^{\prime} / \ln \mathrm{S}$ 
Where

H' Shannon diversity index

$\mathrm{S}$ Total number of species in the area

Equitability assumes a value between 0 and 1 with being complete evenness (Whittaker, 1972).

\section{Results and discussion}

\section{Woody Species composition and diversity}

We recorded 31 (indigenous 18 and exotic 13) and 32 (Indigenous 14 and exotic 18) tree species from KMU compound and Yeka park. Of all tree species, Jacaranda equistifolia and Cupressus lusitanica were the species with the highest density at KMU compound whereas Cupressus lusitanica, Acacia melanoxylon and Grevillea robusta were the species with the highest density at Yeka Park. The overall Shannon-Wiener diversity and evenness values of woody species were 2.76 and 1.96 at KMU compound and 0.63 and 0.0266 at Yeka Park respectively.

\section{Density and basal area}

The total densities of trees/shrubs were 2464 and 1600 individual ha-1 at KMU and Yeka Park, respectively. We recorded the highest density of species from Jacaranda equistifolia (28.5\%) followed by Cupressus lusitanica (8\%). The highest density at Yeka park was Cupressus lusitanica (45\%) followed by Acacia melanoxylon (8.5\%). Among the recorded trees, Jacaranda equistifolia, Cupressus lusitanica, Acacia melanoxylon, Acacia abyssinica and Grevillea robusta were the top five dominant trees that contributed $63 \%$ of the total basal area at KMU. Similarly, Cupressus lusitanica, Acacia melanoxylon, Grevillea robusta, Dovyalis abssinica and Jacaranda mimosifolia were the top five dominant trees that contributed $74 \%$ of the total basal area at Yeka Park.

\section{Diameter distribution pattern}

The maximum and minimum average diameter was $65.67 \mathrm{~cm}$ and $16.52 \mathrm{~cm}$ at Yeka Park, whereas the maximum diameter was $44.55 \mathrm{~cm}$ and $6.51 \mathrm{~cm}$ at KMU compound. Trees that exhibited the largest and smallest diameter were Bersama abyssinica and Persea Americana in Yeka park while Ficus sur and Allophylus abyssinicus were the trees that exhibited the largest and smallest diameter at KMU compound.
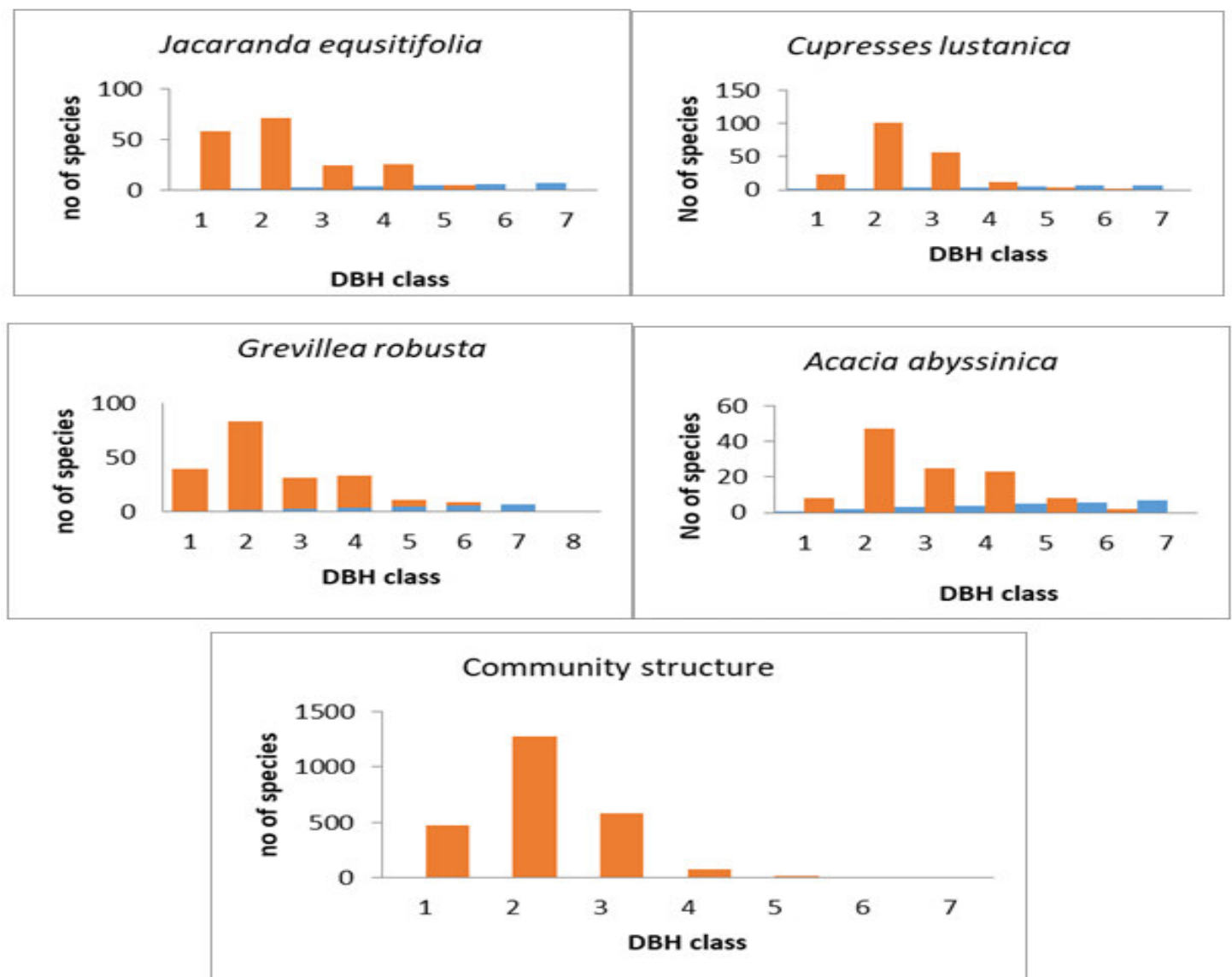

Figure 3. Population structure of the entire community and selected tree species at KMU (DBH class: $1=5-10$, $2=11-20,3=21-30,4=31-40,5=41-50,6=51-60,7>60)$ 

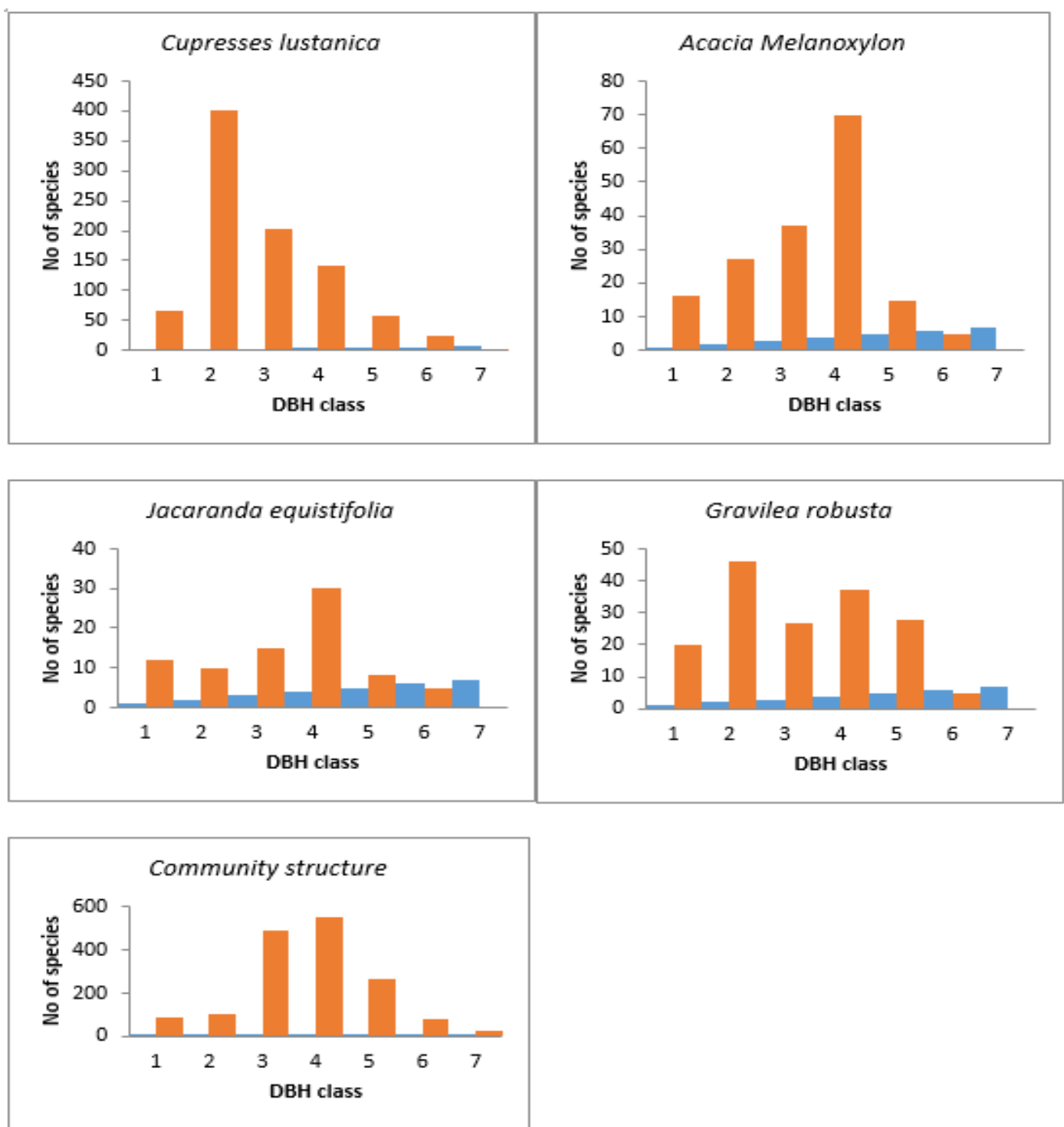

Figure 4. Population structure of the entire community and selected tree species at Yeka Park (DBH class: $1=5$ $10,2=11-20,3=21-30,4=31-40,5=41-50,6=51-60,7>60)$

\section{Above ground biomass and carbon stock}

The mean biomass value recorded in KMU and Yeka Park was $160.77 \mathrm{t} \mathrm{ha}^{-1}$ and $165 \mathrm{t} \mathrm{ha}^{-1}$ respectively. About $83.33 \%$ of the total biomass was contained in the above ground pool whereas, $16.66 \%$ and $17.1 \%$ was contained in below ground pool in KMU and Yeka Park respectively. The total carbon stock (aboveground and belowground) ranged between $160 \mathrm{tha}^{-1}$ and $32 \mathrm{t} \mathrm{C} \mathrm{ha}^{-1}$ with a mean value of $63.52 \mathrm{t} \mathrm{C}^{-1}$ at KMU compound. This value is equivalent to $587.2 \mathrm{CO}_{2} \mathrm{ha}^{-1}$ at $\mathrm{KMU}$ and $605.55 \mathrm{CO}_{2} \mathrm{ha}^{-1}$ at Yeka Park. Among the tree species Ficus sur, Pinus patula, Phoenix reclinata and Acacia abyssinica contributed 30\% of the total above-ground biomass and carbon stock at at KMU compound. Similarly, Bersama abyssinica, Allophylus abyssinicus, Casuarina cunninghaminana, Ficus elastic and Ficus sur contributed $28 \%$ of the total above-ground biomass and carbon stock at Yeka Park.

From the selected study sites the maximum AGB was $165.105 \mathrm{t} \mathrm{ha}^{-1}$ in Yeka Park. Since most of the trees in this park had DBH greater than $30 \mathrm{~cm}$. The AGC, BGC and BGB increases with increasing AGB. The mean biomass values recorded in the study sites were greater than the values recommended by IPCC for tropical dry forest 130.00t ha ${ }^{-1}$ (IPCC, 1997c). KMU has less AGB than Yeka Park due to the dominance of certain species with DBH less than $30 \mathrm{~cm}$. The biomass difference of parks was mainly due to the difference in tree species and the variation in their DBH, the selection of tree types including the management of the trees. AGB and AGC of the study sites are shown on the following table. 
Table 1. Above ground biomass and carbon stock of study sites

\begin{tabular}{|l|l|l|}
\hline Study Sites & AGB & C in ABG $\left(\mathrm{t} \mathrm{ha}^{-1}\right)$ \\
\hline KMU & 160 & 75.57 \\
\hline Yeka Park & 165 & 77.55 \\
\hline
\end{tabular}

\section{Carbon in the below ground biomass}

The below ground carbon stock were $15.04 \mathrm{ha}^{-1}$ in KMU and $15.51 \mathrm{ha}^{-1}$ in Yeka park. KMU is more diversified than Yeka Park though the numbers of exotic species are larger than indigenous species. The below ground biomass of each park is given on the following table below.

Table 2. Below ground biomass and carbon stock of study sites

\begin{tabular}{|l|l|l|l|}
\hline Study Sites & BGB & $\mathrm{C}$ in BGB $\left(\mathrm{t} \mathrm{ha}^{-1}\right)$ & $\mathrm{CO}_{2}$ of BGB $\left(\mathrm{t} \mathrm{ha}^{-1}\right)$ \\
\hline KMU & 32 & 15.04 & 117.44 \\
\hline Yeka Park & 33 & 15.51 & 121.11 \\
\hline
\end{tabular}

\section{Distribution of exotic and indigenous species}

The numbers of indigenous species were larger in KMU than Yeka Park. From total of 31 species 18 were indigenous. Yeka Park had largest number of exotic species than indigenous species. The widely seen exotic species in the study sites were Cupressus lusitanica, Jacaranda mimosifolia, Grevillea robusta and Eucalyptus saligna. The widely seen indigenous species were Juniperous procera, Hagenia abyssinica and Podocarpus falcatus. The number of exotic and indigenous species of the study sites is shown below.

Table 3. Number and density of exotic and indigenous species of each study sites

\begin{tabular}{|l|l|l|l|l|l|l|l|}
\hline No & $\begin{array}{l}\text { Study } \\
\text { site }\end{array}$ & $\begin{array}{l}\text { Total no } \\
\text { of trees }\end{array}$ & $\begin{array}{l}\text { No of } \\
\text { species }\end{array}$ & $\begin{array}{l}\text { No of exotic } \\
\text { species } \\
\text { exotic trees }\end{array}$ & $\begin{array}{l}\text { Density of } \\
\text { indigenous } \\
\text { species }\end{array}$ & $\begin{array}{l}\text { Density of } \\
\text { indigenous trees }\end{array}$ \\
\hline 1 & KMU & 2464 & 31 & 13 & 1587 & 18 & 877 \\
\hline 2 & $\begin{array}{l}\text { Yeka } \\
\text { park }\end{array}$ & 1600 & 32 & 18 & 1363 & 14 & 237 \\
\hline
\end{tabular}

\section{Diversity and evenness of species}

As shown on the table below KMU had more diversified species than Yeka Park. The total number of tress and Species in KMU are much larger than Yeka Park. It has dominance of certain species which reduces the evenness of the park.

Table 5. The diversity, evenness, and total number of species in each Park

\begin{tabular}{|l|l|l|l|l|}
\hline Study Sites & Total Number of Trees & Total Number of Species & H' $^{\prime}$ & $\mathrm{E}_{\mathrm{H}}$ \\
\hline KMU & 2464 & 31 & 2.76 & 0.63 \\
\hline Yeka Park & 1600 & 32 & 1.96 & 0.266 \\
\hline
\end{tabular}

\section{Discussion}

\section{Woody species composition}

The woody species richness (31species and 32species) recorded at KMU and Yeka Park is lower than the findings from Church forests (114 woody species, (Abiyu, Soromessa, \& Belliethathan, 2013) and Woody Plant Species in Biheretsige and Central Closed Public Parks in Addis Ababa (114 species, Marshet, 2013). The observed variation or difference in species richness and diversity among the forests might be due to the differences in size of the areas, year of establishment and the forest conditions

\section{Diameter distribution pattern}

In this study, the majority of tree species exhibited little or no seedlings and while very few tree species showed good regeneration status. The patterns of Diameter at Breast Height (DBH) class distributions indicated the general trends of population dynamics and recruitment processes of the species. From the DBH class distributions of the species, two types of regeneration status were determined, i.e. good and poor regeneration. Some species (Cupressus lusitanica, Jacaranda mimosifolia, Grevillea robusta and Hagenia abyssinica) possessed high number of individuals in the lower DBH classes, particularly in the first class, which suggests that they have good regeneration potential. Other species (Cupressus lusitanica, Jacaranda mimosifolia, and Ficus sur) possessed either no or few number of individuals in the lower DBH classes, particularly in the first class, which indicates that the species are in poor regeneration status.

\section{Above ground biomass of the study sites}

The aboveground biomasses of the studied forests were higher than Woody Plant Species in Biheretsige and 
Central Closed Public Parks in Addis Ababa (149.18 t ha-1, Marshet, 2013) or comparable with the values reported from church forests, in Ethiopia $330.6 \mathrm{t} \mathrm{ha}^{-1}$ (Abiyu et al., 2013). This variation could be explained due to number of species the year of establishment and also differences in the size of the areas. The AGB of species depend on their DBH value and also on their age. The older trees with large DBH value will have large AGB. As age of tree increase biomass also increase (Negash, 2007).

\section{Conclusion}

The two forests act as a refuge site for a variety of indigenous and endangered dry Afromontane forest trees (16 species at KMU and 32 species at Yeka park) as well as the commonly known exotic tree species (18 species). They also complimented the potential roles of forests for climate change mitigation activities by storing $75.57 \mathrm{t}$ $\mathrm{ha}^{-1}$ and $77.55 \mathrm{t} \mathrm{ha}^{-1}$ at KMU and Yeka Park respectively. Furthermore, the observed species and family richness in both forests make the areas a potential candidate for in-situ conservation sites for the conservation of endangered indigenous tree species.

Recommendations

The following recommendations were forwarded:

- Reduce the number of exotic tree species and set aside the two sites as an in-situ site for the conservation of indigenous tree species

- Increase the number and diversity of indigenous tree species through plantation development

- Consider the role of these forests for climate change mitigation and REDD+ projects

- Attention is needed to be given for urban forests

\section{References}

Abiyu, A., Soromessa, T., \& Belliethathan, S. (2013). The Role of Church Forest for Carbon Emission Reduction, Climate Change Mitigation and Urban Greenery: The Case of Selected Churches in Addis Ababa, Ethiopia.

Alvey, A. A. (2006). Promoting and preserving biodiversity in the urban forest. 5(4), 195-201.

Arsiso, B. K., Tsidu, G. M., Stoffberg, G. H., \& Tadesse, T. (2018). Influence of urbanization-driven land use/cover change on climate: The case of Addis Ababa, Ethiopia. 105, 212-223.

Bekele, H. J. R. I. o. T. S., Sweden. (2005). Urbanization and urban sprawl.

Bolund, P., \& Hunhammar, S. J. E. e. (1999). Ecosystem services in urban areas. 29(2), 293-301.

Brown, S., Gillespie, A. J., \& Lugo, A. E. J. F. s. (1989). Biomass estimation methods for tropical forests with applications to forest inventory data. 35(4), 881-902.

Chave, J., Réjou - Méchain, M., Búrquez, A., Chidumayo, E., Colgan, M. S., Delitti, W. B., .. . Goodman, R. C. J. G. c. b. (2014). Improved allometric models to estimate the aboveground biomass of tropical trees. 20(10), 3177-3190.

Cohen, B. J. T. i. s. (2006). Urbanization in developing countries: Current trends, future projections, and key challenges for sustainability. 28(1-2), 63-80.

Escobedo, F. J., Kroeger, T., \& Wagner, J. E. J. E. p. (2011). Urban forests and pollution mitigation: Analyzing ecosystem services and disservices. 159(8-9), 2078-2087.

Fetene, A., \& Worku, H. (2013). Planning for the conservation and sustainable use of urban forestry in Addis Ababa, Ethiopia. Urban forestry urban greening, 12(3), 367-379.

Gezahegne, G. (2014). The Status of Green spaces and Green space Participatory Management in the City of Addis Ababa Msc Programme in Urban Management and Development Rotterdam, The Netherlands.

Gómez-Baggethun, E., \& Barton, D. N. J. E. E. (2013). Classifying and valuing ecosystem services for urban planning. 86, 235-245.

Gratani, L., Varone, L., Bonito, A. J. U. F., \& Greening, U. (2016). Carbon sequestration of four urban parks in Rome. 19, 184-193.

Horst, A. J. J. o. t. D. (2006). Rehabilitation of urban forests in Addis Ababa. 1(2), 108-117.

IPCC. (2014). Summary for policymakers. In: Climate Change 2014: Impacts, Adaptation, and Vulnerability. Part A: Global and Sectoral Aspects. Contribution of Working Group II to the Fifth Assessment Report of the Intergovernmental Panel on Climate Change

Jim, C. Y., \& Chen, W. Y. J. J. o. e. m. (2008). Assessing the ecosystem service of air pollutant removal by urban trees in Guangzhou (China). 88(4), 665-676.

Konijnendijk, C. C., Sadio, S., Randrup, T. B., \& Schipperijn, J. J. J. o. a. (2004). Urban and peri-urban forestry in a development context-strategy and implementation. 30(5), 269-276.

Kuchelmeister, G. (1997). Urban trees in arid landscapes: Multipurpose urban forestry for local needs in developing countries. Arid Lands Newsletter, 42.

Kuchelmeister, G. (2000). Trees for the urban millennium: urban forestry update. UNASYLVA-FAO-, 49-55.

Kuchelmeister, G. J. U.-F.-. (2000). Trees for the urban millennium: urban forestry update. 49-55. 
Liu, C., Li, X. J. U. F., \& Greening, U. (2012). Carbon storage and sequestration by urban forests in Shenyang, China. 11(2), 121-128.

MacDicken, K. G. (1997). A guide to monitoring carbon storage in forestry and agroforestry projects.

MillenniumEcosystemAssessment. (2005). Ecosystems and human well-being: our human planet: summary for decision-makers (Vol. 5): Island Pr.

Nowak, D. J., \& Crane, D. E. J. E. p. (2002). Carbon storage and sequestration by urban trees in the USA. 116(3), 381-389.

Pearson, T., Walker, S., \& Brown, S. (2013). Sourcebook for land use, land-use change and forestry projects.

Tsutsumi, J., \& Bendewald, M. (2010). Urban environmental challenges in developing cities: the case of Ethiopian capital Addis Ababa. World Academy of Science, Engineering

Technology, International Journal of Environmental, Chemical, Ecological, Geological Geophysical Engineering, 4(6), 164-169.

Tyrväinen, L., Pauleit, S., Seeland, K., \& de Vries, S. (2005). Benefits and uses of urban forests and trees. In Urban forests and trees (pp. 81-114): Springer.

Walker, C. (2004). The public value of urban parks: Urban Institute.

Wilsey, B. J., \& Potvin, C. J. E. (2000). Biodiversity and ecosystem functioning: importance of species evenness in an old field. 81(4), 887-892. 